\title{
Optimal Design of Shunt Active Power Filter for Power Quality Improvement Based on Virtual Experimental Filter Technique
}

\section{Eid Gouda ${ }^{1}$, H. EI Sharabasy ${ }^{2}$, Fareed N.Abdalber ${ }^{3}$, Gaber El Saady ${ }^{3}$}

${ }^{1}$ Electrical Engineering Department Faculty of Engineering

Mansoura University, Egypt

${ }^{2}$ Electrical Power Engineer at Engineering Department DK Sugar

Company, Egypt

${ }^{3}$ Electrical Engineering Department, Faculty of Engineering, ASSUIT University, Egypt

\begin{abstract}
Nowadays active power filter (APF) is well known technique for improving the power quality .It mitigates the level of harmonics to acceptable ratio, also it overcomes voltage sag and improves power factor. There are different types of APF according to its application. This paper will introduce a detailed design of a Shunt Active Power filter (SAPF). Firstly trial and error method will be used to select acceptable value for conventional filter PI controller parameters, Secondly particle swarm optimization (PSO) technique is used for tuning the filter PI controller by optimizing the optimal controller gains. The presented design is modeled and simulated by using MATLAB-SIMULINK toolbox. Many contributions such as design and simulation of SAPF, besides practical modeling of a nonlinear load for studying the effect of SAPF on the integrated system. A practical verification is done and compared to the proposed simulated system. It is found that a good agreement between the experimental result and the modeled one. A costless method based on Virtual experimental technique is also used and applied to large scale systems for obtaining predesign system with acceptable accuracy. The proposed filter can be adapted for any other loads with acceptable total harmonic distortion (THD) under the norms of IEEE (519-1992).
\end{abstract}

Keywords: Shunt Active Harmonic Filter, PI controller, PSO and THD 


\section{Introduction}

Recently the importance of SAPF increased to overcome some of the system power quality violation caused by different types of nonlinear loads of modern technology. The IEEE (5191992) standard gives indication for harmonic limits at the point of common coupling (PCC) between the source and load to the acceptable range [1]. Use of non-linear electrical devices and timevarying loads resulted in distortion of voltage and current wave forms and more using of reactive power in network [2]. The acceptable design of a filter is become more essential for distribution systems. This paper deals with the design and optimization of filter components and parameters in such a way that decreasing the total cost, correcting undesirable voltage profile and return total harmonic distortion to its permissible value according to The IEEE (519-1992).Passives filters were also used to mitigate the current harmonic distortion but on the contrary with active filter it had many disadvantages like large component size, fixed compensation, power losses and the possibility of resonance with the impedance of supply [3][4]. The control circuit of SAPF in this paper is based on the instantaneous power theory (PQ theory) where the used controller is responsible for estimating the compensating currents needed to be injected to the system to compensate the harmonics that produced from nonlinear loads [2].Many optimization techniques are made on to find the best values for PI controller terms proportional term $\left(\mathrm{K}_{\mathrm{P}}\right)$ and integral term $\left(\mathrm{K}_{\mathrm{I}}\right)$ [5]. With a proper values to $K_{P}$ and $K_{I}$ the system will work on the Minimum total harmonic distortion value (THD) and allows the supply system to work with more nonlinear loads.

Optimization techniques help in optimizing PI controller parameters where every value of $K_{P}$ and $K_{I}$ changes THD value till reach to the minimum value. PSO one of the well-known Optimization techniques, proposed by Dr. Kennedy and Ebehart in the year 1995 [6], and was used to get the minimum THD in waveforms for proposed nonlinear load with the help of MATLAB Simulink. PSO technique was used in many other researches [7-8] and proves its validity. 
According to filter topology there are two power filter types, SAPF and series Active Filter [9]. SAPF used to reduce current harmonics in system supply [10] and series filter help in Improving the voltage quality .In this approach SAPF will be used with nonlinear load where SAPF measures the load currents and voltages and generates compensation currents to decrease the harmonics present in the system [11].

\section{This research can contribute the following:}

1) Design and simulation of SAPF

2) Experimental modeling and simulation of nonlinear load

3) Studying the effect of SAPF integrating to the nonlinear load.

4) Virtual experimental technique which is a cost less method which can be applied with large systems to obtain predesign system with acceptable accuracy.

This paper is categorized into five sections as follows: section.I is an overview, section.II introduces the PSO algorithm. Section.III and IV explain both the SAPF design and system modeling with help of simulation results with comments. The final concentrated points and results are introduced through the conclusion in section. $\mathrm{V}$.

\section{PARTICLE SWARM OPTIMIZATION ALGORITHM}

The main issue for optimization is to find the best solution to a problem by using a given set of values .PSO is one of the best methods comes from nature used to solve the optimization problems that extracted from birds and fish searching food behaviors [6]. The presented method is used to optimize the SAPF parameters to obtain a higher performance. PSO solves a problem by trying to collect randomly a set of different solutions, and try to update it every time to get the best result. The single solution in the search space is called particle. Fitness values for particles are estimated by the fitness function for optimization, and have velocities which direct the flying of the particles. By PSO method The velocity and the best position achieved by each particle in the swarm to all other particles which is represented by Equation.(1) and (2), respectively. 


$$
\begin{aligned}
& V_{g(t+1)}=W_{g}(t)+C_{1} P_{1}\left(P_{b s t}-X_{g}(t)\right)+ \\
& G_{2}\left(G_{n t}-X_{g}\right) \\
& Z_{g}(t+1)=Z_{g}(t)+V_{g}(t+1)
\end{aligned}
$$

Where $\mathrm{V}_{\mathrm{s}(\mathrm{t})}$ is the velocity of particle $\mathrm{s}$ in $\mathrm{t}$ time, $\mathrm{X}_{\mathrm{s}(\mathrm{t})}$ is the position vector of particle $\mathrm{s}$ in $\mathrm{t}$ time; $\mathrm{P}_{\text {best }}$ is the personal best position, $G_{\text {best }}$ is the best position of the particle at present; $w$ is the inertia weight; $c_{1}, c_{2}$ are acceleration constants, named cognitive and social parameters respectively, $r_{1}$ and $r_{2}$ represent the random functions within limit $[0,1]$.

The main purpose of this paper is to concern on the minimization of THD by using PSO optimization theory to get the optimum values of PI controller parameters $K_{P}$ and $K_{I}$ for mitigating the undesirable harmonics. The main fitness function will be studied in this paper as shown in Equation(3):

$$
\mathrm{F}=F_{\text {THD }}
$$

The following PSO algorithm shown in Fig.1 indicates the procedure of $\mathrm{K}_{\mathrm{P}}$ and $\mathrm{K}_{\mathrm{I}}$ optimization.

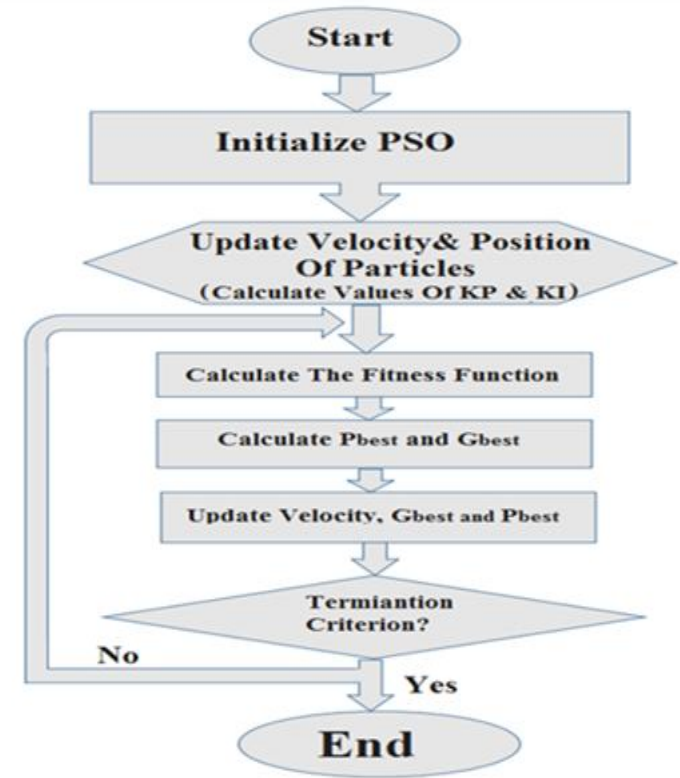

Fig.1. PSO Flow chart for KP and KI optimization. 


\section{Shunt Active Filter Design}

Fig. 2 shows SAPF component with the supply and the nonlinear load and Fig. 3 shows the simulation diagram of its control part .The load configuration and the system parameter used in this paper is listed in Table.1 where the load used is a three phase rectifier with resistive load that represents the nonlinear load and the filter is SAPF.

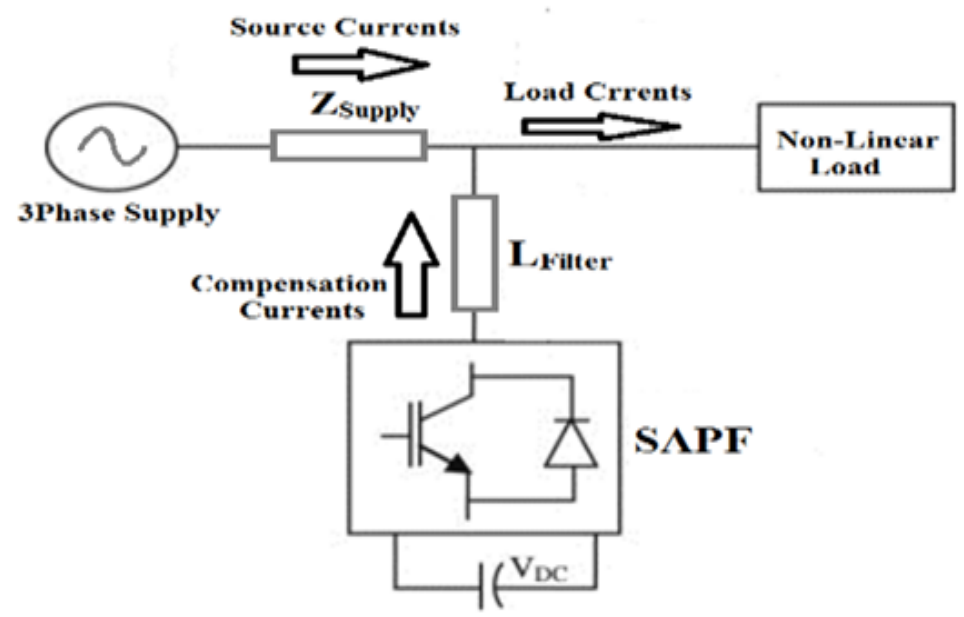

Fig.2 SAPF Components

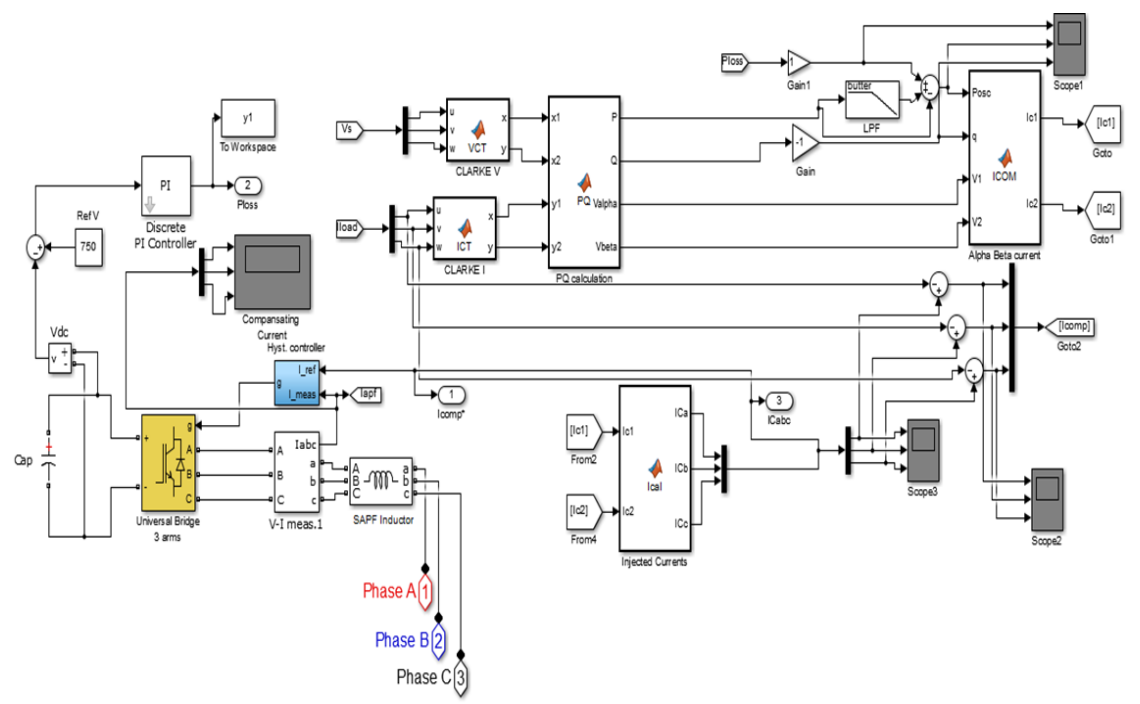




\subsection{Component sizing}

\section{(1) DC Voltage selection}

To guarantee a good compensation from the Active filter to the system the dc bus voltage should be greater than the phase peak voltage of the system reaches to the twice of its value Equation.(4) used to calculate the dc bus voltage[12].

$$
V_{d c}=\frac{2 \sqrt{2}}{\sqrt{3}} \frac{V_{L L}}{m}
$$

Where, $\mathrm{V}_{\mathrm{LL}}$ is the line voltage of source that including harmonics and $\mathrm{m}$ represent the modulation index $\mathrm{m}=1$.

\section{1) DC Capacitor selection}

To calculate the value of the dc capacitor from the DC voltage reference (Vdc) Equation.(5) is used [13].

$$
\frac{1}{2} C\left[\left(V_{d c}\right)^{2}-\left(V_{d c 1}\right)^{2}\right]=3 V(a I) t
$$

Where, Vdc1, a, V and I are the minimum voltage of dc bus, the factor of over loading, the phase voltage and current respectively where a taken as 1.2. The time taken by the dc bus voltage to be recovered is $\mathrm{t}$

(3) Filter inductance selection

The main function of the filter inductance introduced in SAPF is to reduce the ripples and high frequency component of the compensating current and taking into consideration that the injected current di/dt generated by the SAPF is greater than the reference compensating current to follow its reference. By determining the ripple current and switching frequency filter the approximate value of inductance can be calculated according to Equation. 6 .

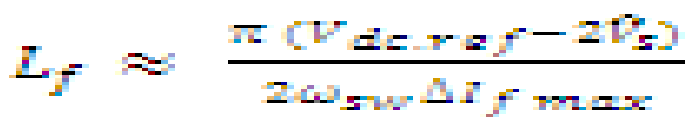

Where the value of maximum ripple $\Delta$ If $\max$ is $15 \%$ of the filter current and $\omega_{\mathrm{sw}}$ is the switching frequency [13]. 


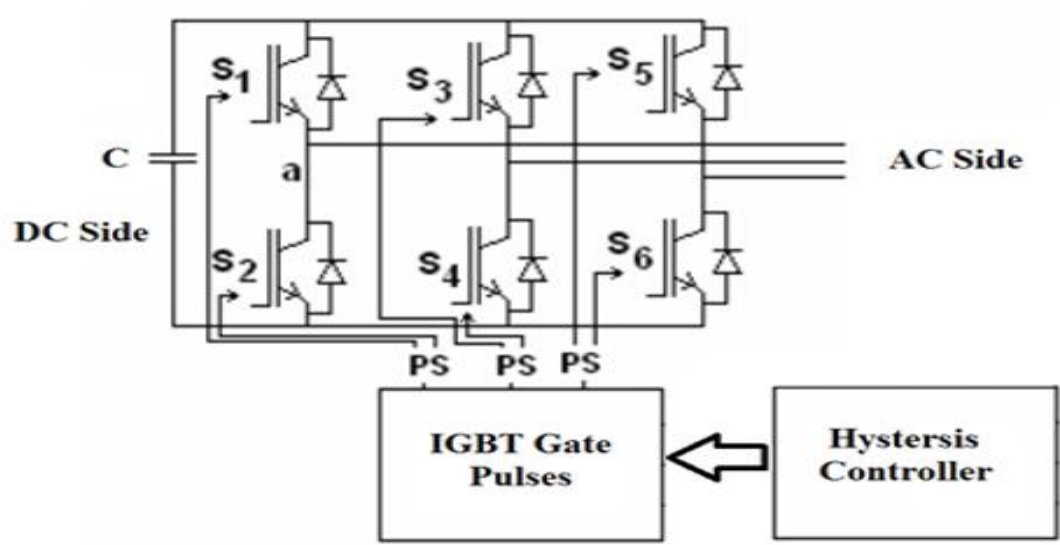

Fig.4. The pulses to the inverter IGBTs using hysteresis current control

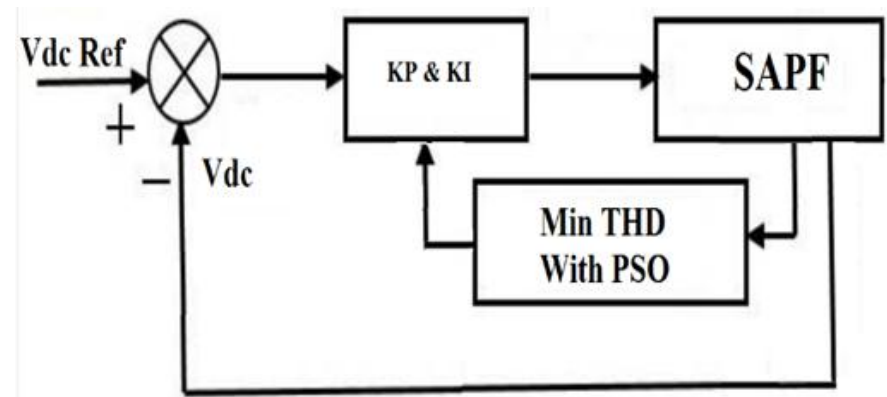

Fig.5. The proposed system with PSO.

\section{A.Proposed Filter system control}

SAPF control includes different types of control techniques and controllers. PI and hysteresis controllers are used and simulated in the proposed SAPF as shown in Fig.3.

\section{1) Instantaneous Power Theory}

The control technique of SAPF used in this paper is based on the PQ theory where it aims to find a strategy to compensate harmonic currents that produced by nonlinear loads using active power filters. The compensating current signals are produced by comparing these currents with filter currents in hysteresis controller [2][3]. 
2) Hysteresis Current Controller

Hysteresis current controller (HCC) is used to send the switching signals to the IGBT of filter inverter. Fig.4 shows the IGBT's inverter, the inverter pulses are generated based on HCC. HCC works independently for each phase of the filter inverter. This controller makes comparison between the actual source currents and the desired reference currents to generate the error current $(\Delta \mathrm{I})$. If $\Delta \mathrm{I}$ exceeds the upper limit of the hysteresis band, the upper IGBT is $\mathrm{OFF}$ and the lower IGBT is ON. If the error current falls to the lower limit of the band, the upper IGBT is ON and lower IGBT is OFF and the same action are repeated for other phases. Finally, the filter can compensate the harmonic currents detected in the source . PI Controller.(3) PI controller is the most important part in the control process of SAPF, the capacitor voltage ( $\mathrm{Vdc}$ ) is sensed and compared with the reference value (Vdcref ). The PI controller Input is the error value (e), Where $\mathrm{e}(\mathrm{t})=\mathrm{Vdcref}-\mathrm{Vdc}$, and the output, after a specified limit, is the magnitude of peak reference current (max I) as Fig.5 indicates. From Equation.(3) it's observed that the minimization of THD is main target of this work and it will be the fitness function. The PI controller output $u(t)$ is given by Equation.(7) :

$$
\mathrm{u}(\mathrm{t})=K_{\mathrm{p}} e(t)+K_{\mathrm{i}} \int_{0}^{\mathrm{t}} e(t) d t
$$

, And its Transfer function is:

$$
\mathrm{G}(\mathrm{S})=\mathrm{KP}+\frac{\mathrm{Kl}}{8}
$$

The main issue in PI controller design is to get the desired values of its gains $\mathrm{K}_{\mathrm{P}}$ and $\mathrm{K}_{\mathrm{I}}$ for the best performance of filter .By PSO technique these values can be obtained. Fig.1 shows the PSO flow chart to optimize the $\mathrm{K}_{\mathrm{P}}$ and $\mathrm{K}_{\mathrm{I}}$ values

\section{MODELING OF PORPOSED SYSTEM}

The proposed modeling strategy can be summarized in the following steps:

1) Design an experimental nonlinear load then the values of power quality elements Voltage, Current, Power Factor and THD are measured and recorded with a suitable device with a good accuracy as Fluke 435 quality meter. 
2) Design and simulate of the nonlinear load in the previous step in the environment of Matlab Simulink to obtain the same previous measurements.

3) Using the virtual technique where the proposed filter designed in Fig.4 added to the simulation load to study its effect on the quality of the system under study.

\section{B. Experimental load Identification}

Typical 400V 50HZ system with balanced nonlinear load developed in laboratory to be analyzed with quality meter .The experimental load taken as example for nonlinear load will be pure resistance with three phase diode bridge rectifier. Fig.6 shows schematic diagram to the target system connected with analyser. The parameters of the supply, cable and load are listed in Table.1.

The type of diodes used with three phase rectifier is SEMIKRON (SKKH72). The results are taken with Fluke 435 power quality analyser and the AC line voltages and currents are sensed using Fluke leads and clamps supplied with the device. The Fig.7 shows the proposed system connected with the analyzer

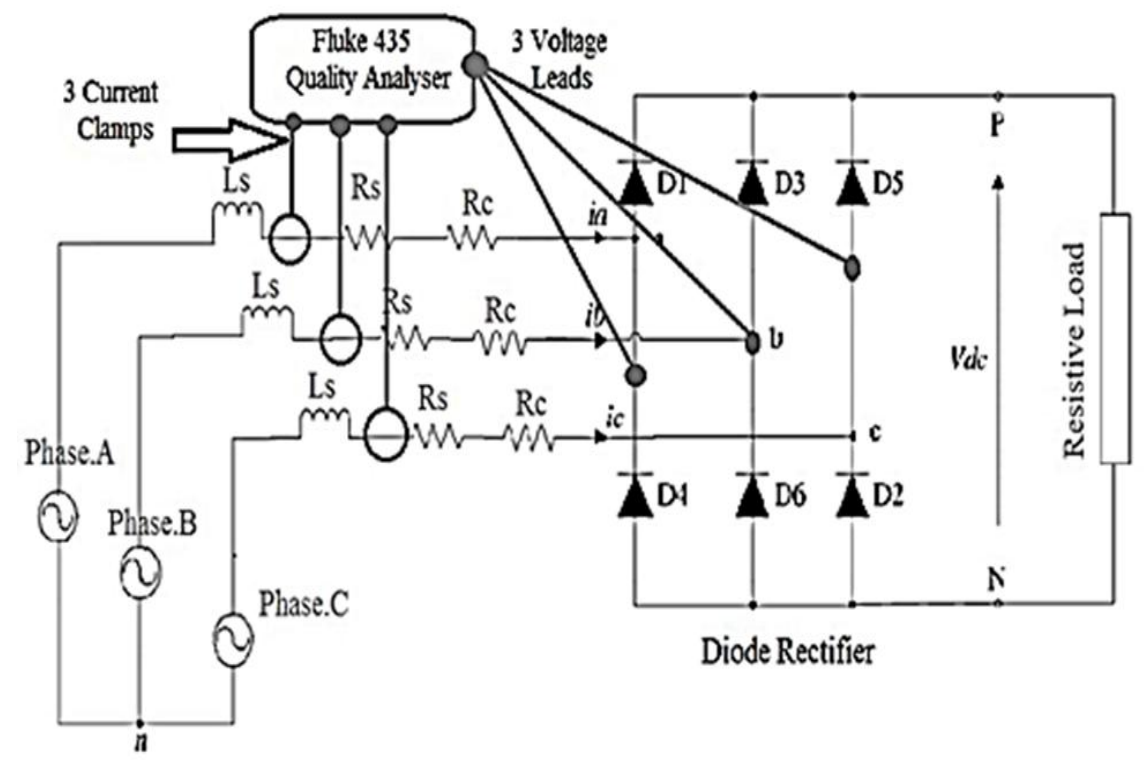

Fig.6. Connection of System with quality analyser 
Table 1. System and load Parameters.

\begin{tabular}{|c|c|}
\hline PARAMETER & VALUE \\
\hline $\begin{array}{l}\text { Source side } \\
\text { Supply3Ф transformer: } \\
\text { Resistance (RS): } \\
\text { Inductance (LS): }\end{array}$ & $\begin{array}{l}\text { 400V,50HZ, } \\
0.001 \text { ohm } \\
\text { 1e-8 H }\end{array}$ \\
\hline $\begin{array}{l}\text { Cable } \\
\text { Resistance (Rc) }\end{array}$ & 0.01 ohm \\
\hline $\begin{array}{l}\text { Load side } \\
3 \Phi \text { diode bridge rectifier } \\
\text { Load Resistance ( } R L\end{array}$ & $43 \mathrm{ohm}$ \\
\hline
\end{tabular}

Equation.(9) used to calculate transformer Rs and Ls.

$$
Z=R s+j X s=\left(\frac{V^{2}}{V A_{30}}\right) * Z_{t x} \%
$$

Where,

$V A_{\text {as }}$ :The rating of the transformer in Volt-Amber,

$\mathrm{Z}_{\mathrm{tx}}$ : Percent impedance in transformer name plate,

Rs : Transformer resistance,

Xs : Transformer reactance,

$\mathrm{V}$ : Phase-to-phase voltage (V),

Taking $\mathrm{X} / \mathrm{R}=5$ (for typical transformer) to get the Ls value.

, Equation.(10) Used to calculate cable resistance(Rc).

Where,

$$
R_{C}=\rho \frac{L}{A}
$$

$\rho$ : Specific resistance for copper $(0.01851 \Omega \mathrm{mm} 2 / \mathrm{m})$.

$\mathrm{L}$ : length of the conductor $(\mathrm{m})$.

A : Cable cross section ( $\mathrm{m} 2)$. 


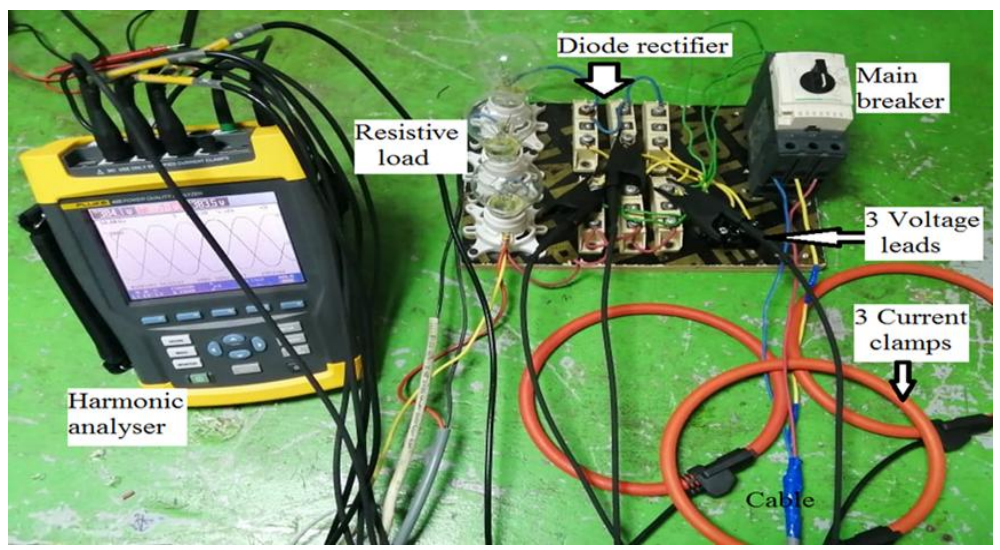

Fig.8 shows the measurements taken by the power quality analyser

Fluke435 after switching on the load where the total harmonic distortion in three phase supply currents is (THD=30\%) and the profiles of three phase waves of currents and voltages are also included in the same figure
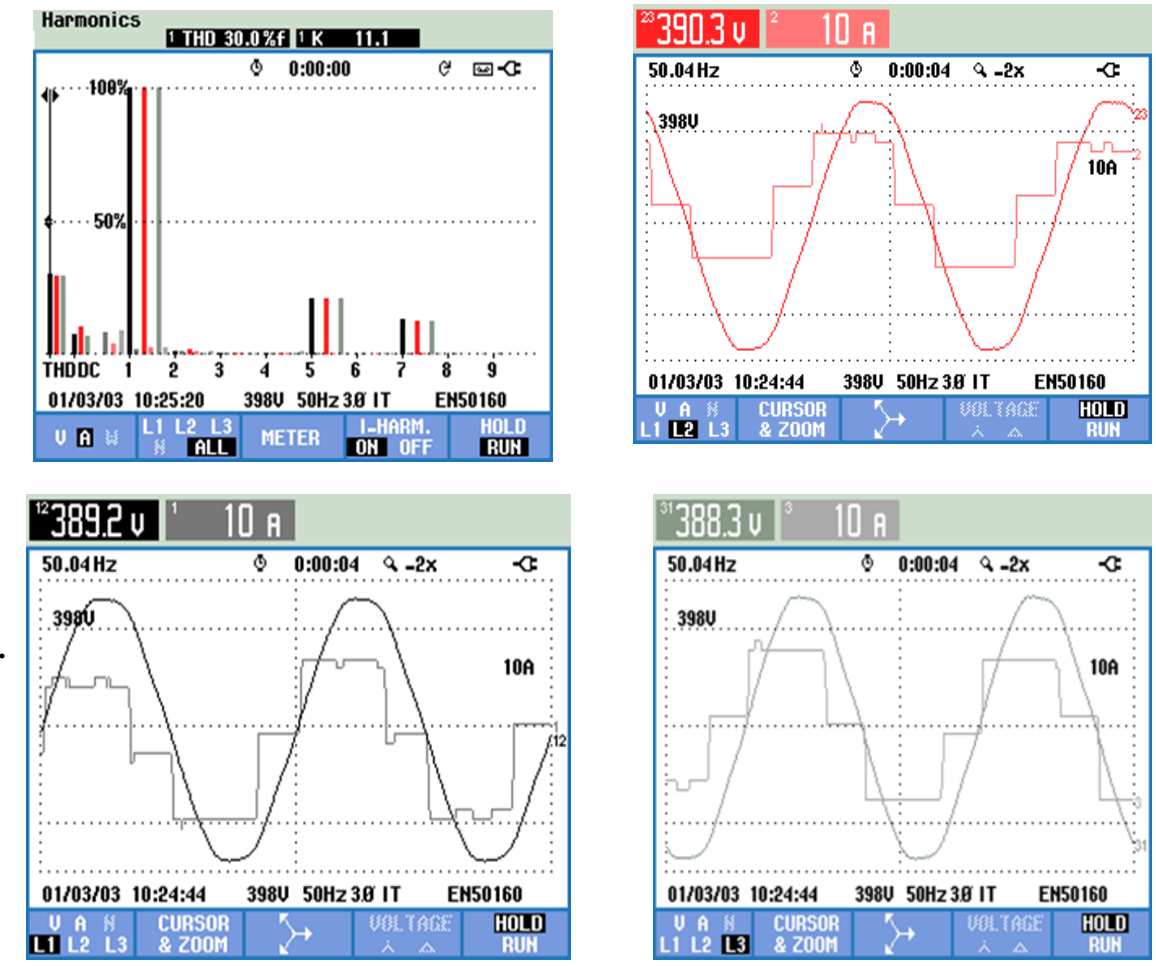

Fig.8. Three Phase THD, Current and Voltage of supply. 


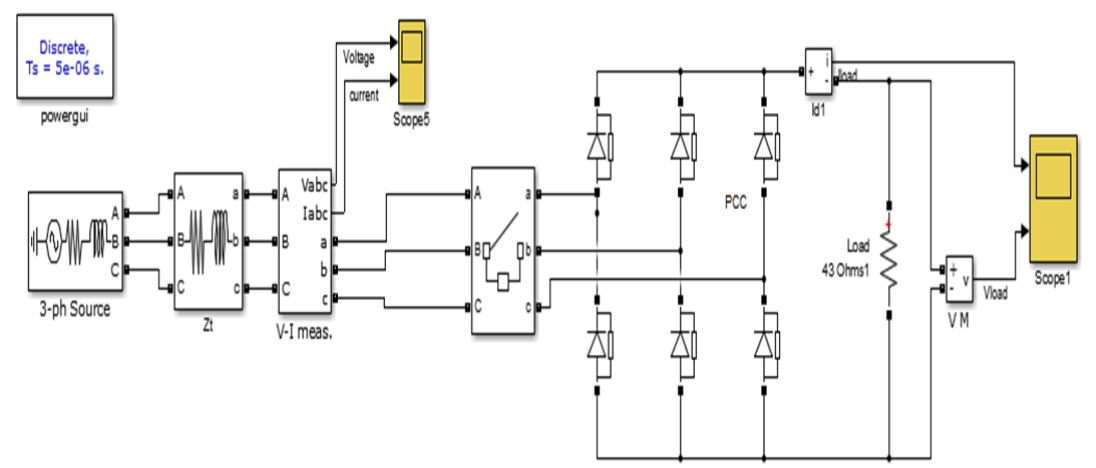

Fig.9. The Simulink Model of the system without SAPF.

\section{C.Matlab simulation results for the load under study}

To check the validation and reliability of SAPF on power quality the same experimental load and system with the same parameters on Table.1 will be modeled with MATLAB/Simulink software package. The characteristics and properties of the supply current and voltage at point of common coupling (PCC) without SAPF will be recorded and compared with the previous experimental measurements to prove the similarity. Fig.9 indicates the Simulink model for the system and the nonlinear load without SAPF where a three phase source connected to the nonlinear load directly.

From the simulation results in Fig.11 and Fig.12, there's a high harmonics distortion during the system operation nearly $30 \%$ for the three phase source currents as the experimental measurements gives.

\section{D.System with SAPF controlled by PI- controller.}

This part discusses and illustrates the response of the system after using SAPF with random selection of PI Controller parameters. The parameter of the SAPF are listed below in Table. 2 and the Simulink model in Fig. 10.

With SAPF without PSO tuning THD decreased to $9.5 \%$ as shown in Fig.14. 
Table 2. SAPF Parameter.

\begin{tabular}{|c|c|}
\hline System Parameters & Value \\
\hline Filter Inductance & $3.3 \mathrm{mH}$ \\
DC Capacitance & $40 \mathrm{FF}$ \\
DC Reference Voltage(Vdc) & $750 \mathrm{~V}$ \\
\hline
\end{tabular}

E. System with SAPF controlled by PI controller based on PSO tuning.

Using PI Controller based on PSO tuning gives more improvement to the filter performance .Table. 3 shows the PSO parameters used for verifying the performance of the PSO-PI controller. The curve of cost function represent THD value with respect to number of iterations, is plotted and shown in Fig.15. THD value by using PSO technique is 5.5441\%, as shown in Fig. 17 for gains $\mathrm{KP}=16.884$ and $\mathrm{KI}=2.0737$ all are obtained after 100 iterations compared with THD $=9.5 \%$ before using PSO. For this particular values of THD value is acceptable under the norms of IEEE.

\section{Table 3. PSO Parameters}

\begin{tabular}{|c|c|}
\hline PSO Parameters & Value \\
\hline No. of birds & 30 \\
Iterations & 100 \\
W & 0.9 \\
C1 & 2 \\
C2 & 2 \\
Problem dimensions & 2 \\
\hline
\end{tabular}




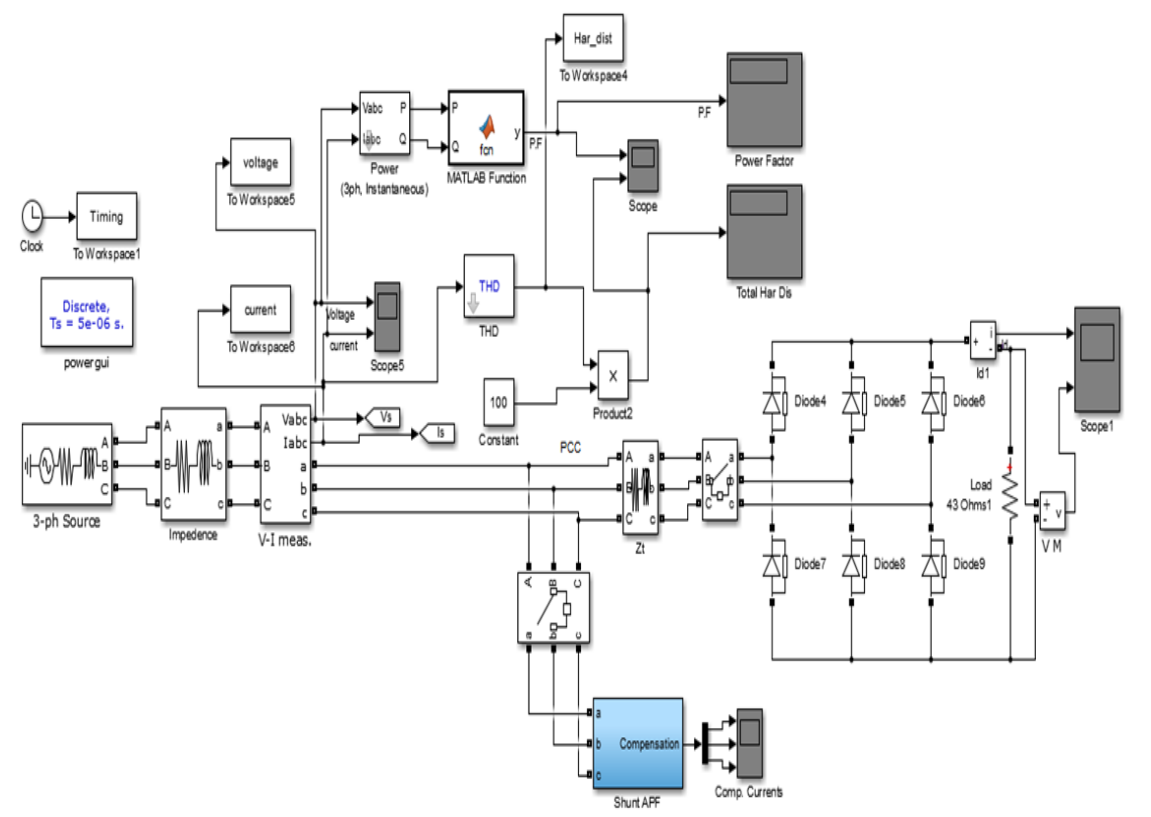

Fig.13. Simulink model for load with SAPF
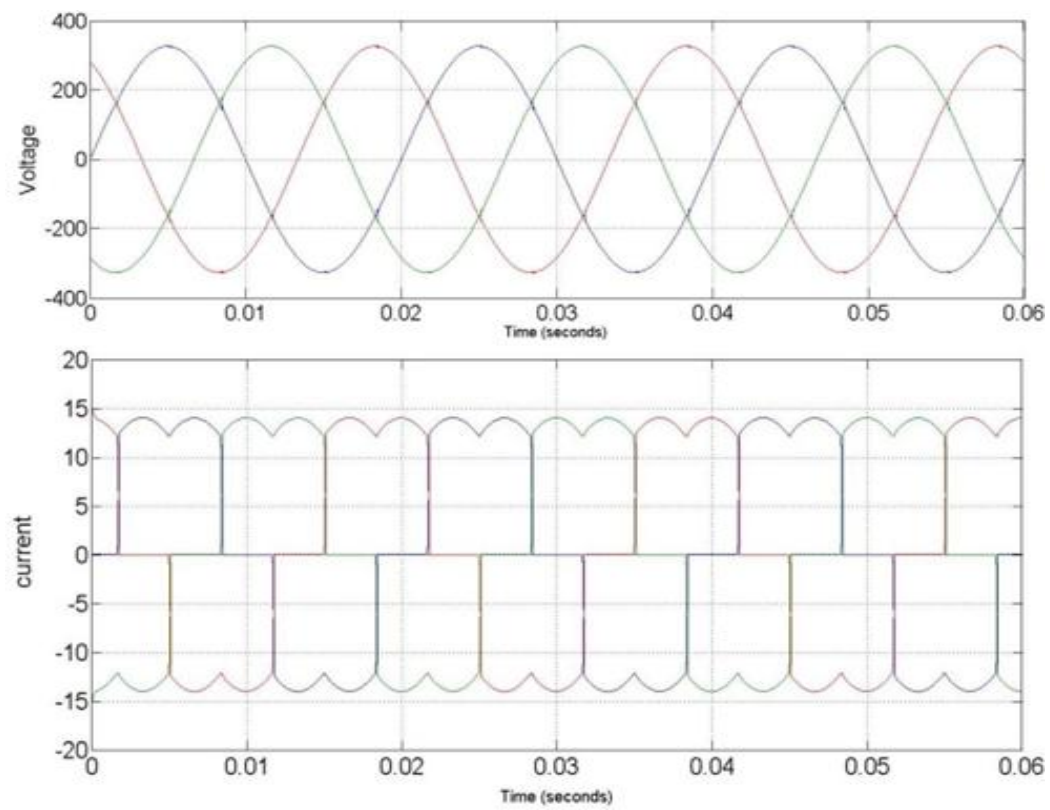

Fig.11. Three Phase Voltage and Currents Waveforms before compensation 
101 Optimal Design of Shunt Attive Power Filter ... 87 - 107

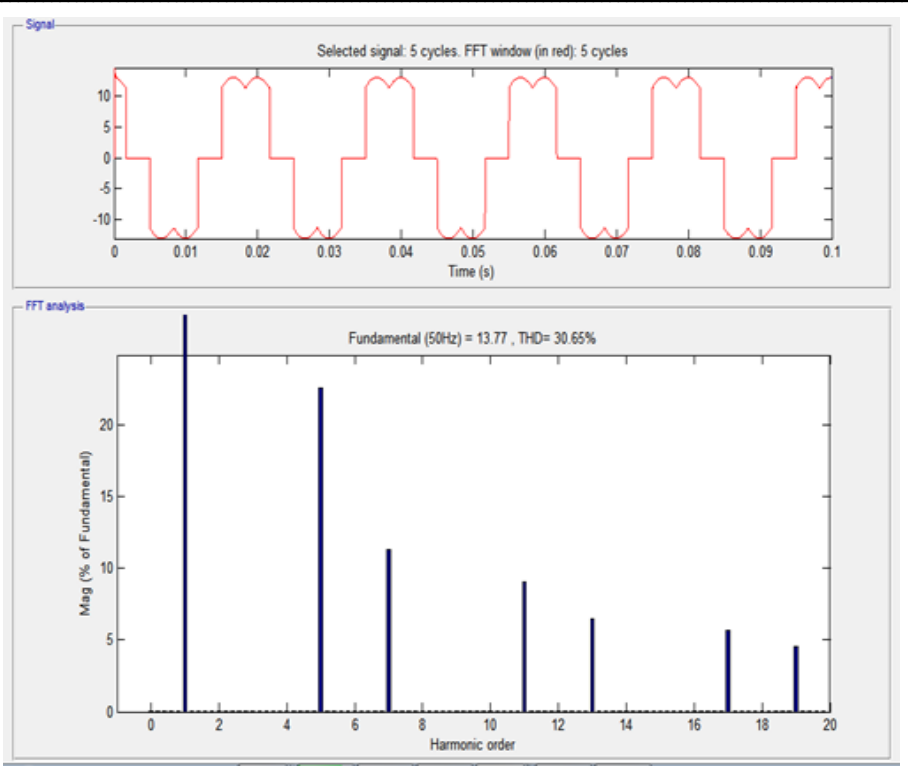

Fig.12. Harmonic spectrum of source current without SAPF

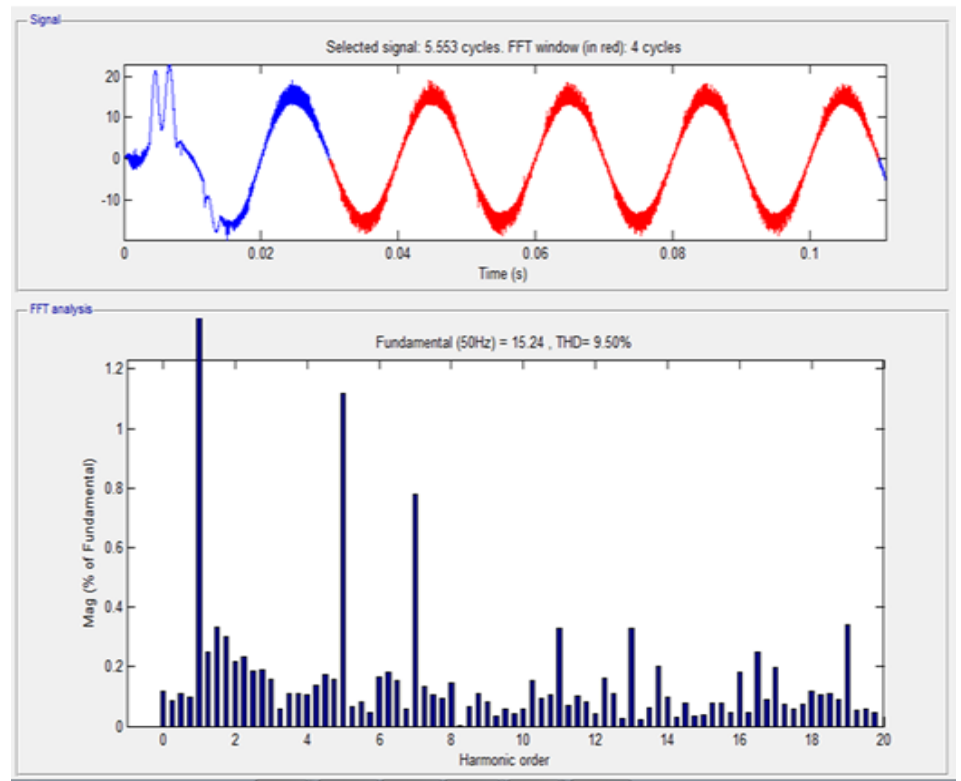

Fig.14. Source current waveform and its THD with using SAPF 


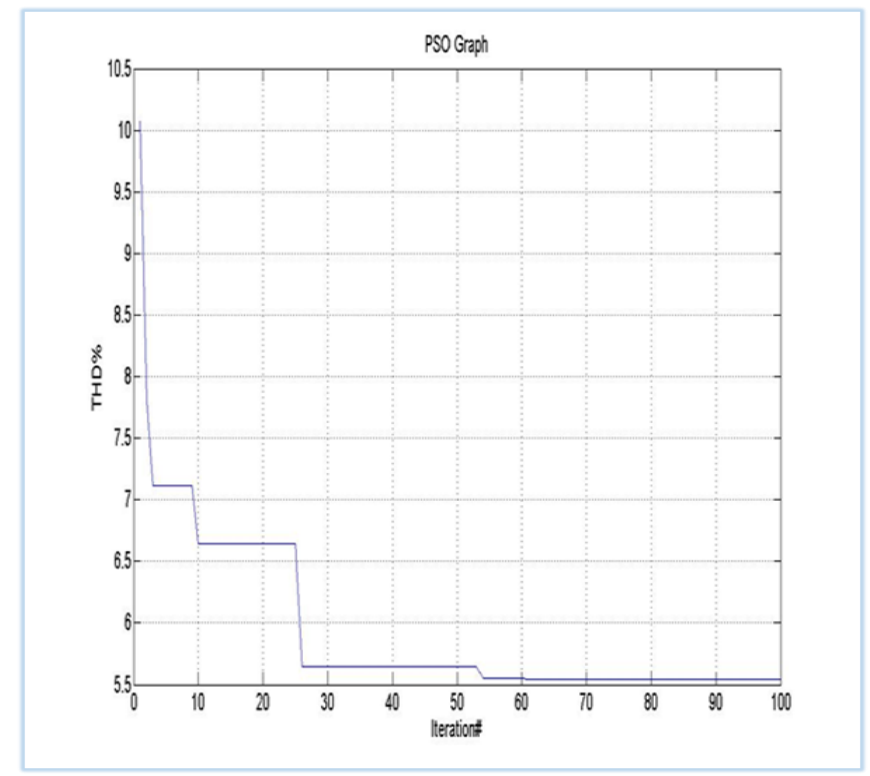

Fig.15. The PSO Graph for 100 iteratio
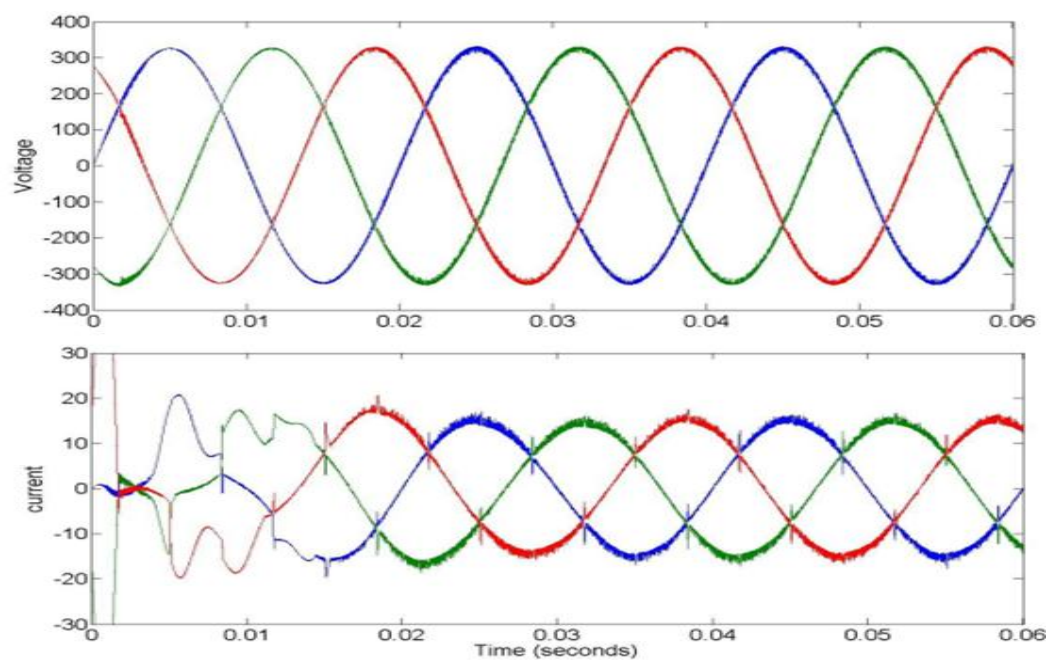

Fig.16. The three phase current and voltage after compensating. 


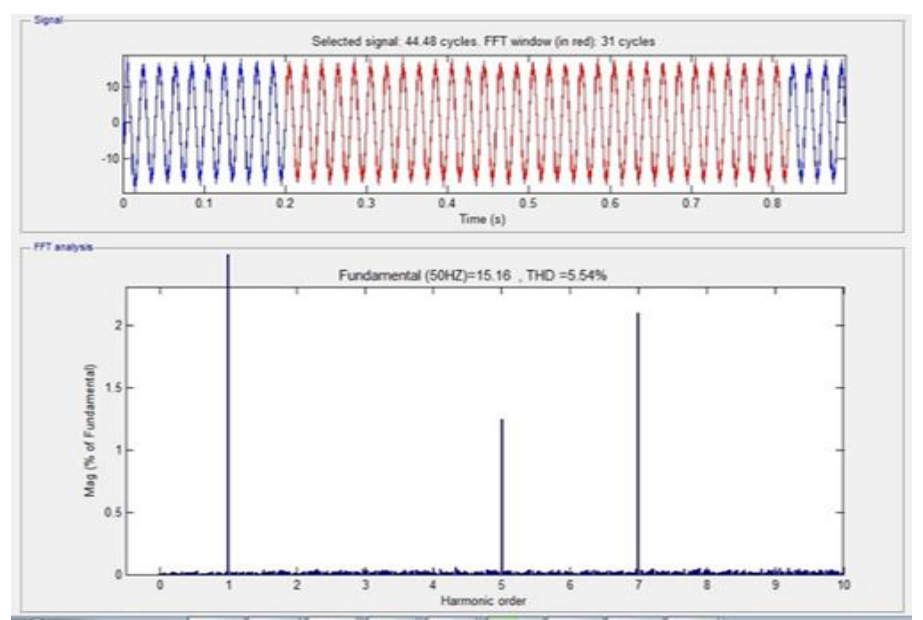

Fig.17. Harmonic spectrum of source current with SAPF

Fig.16 shows the voltage and current waves of the supply at PCC it's found that by applying SAPF the current waves becomes more sinusoidal better than the wave in Fig11. Fig.18 Indicates on the same scope the improvement occurred to the system before and after compensating where the SAPF-PSO connected to the system at $(\mathrm{T}=0.07 \mathrm{~S})$. Fig. 18 shows the three phase source voltage and current before and after compensating. Fig. 19 shows the improvement occurred to the THD and power factor PF values where THD falls from $30 \%$ to about $5 \%$ and the improvement occurred to the value of power factor from below 0.96 to near unity power factor
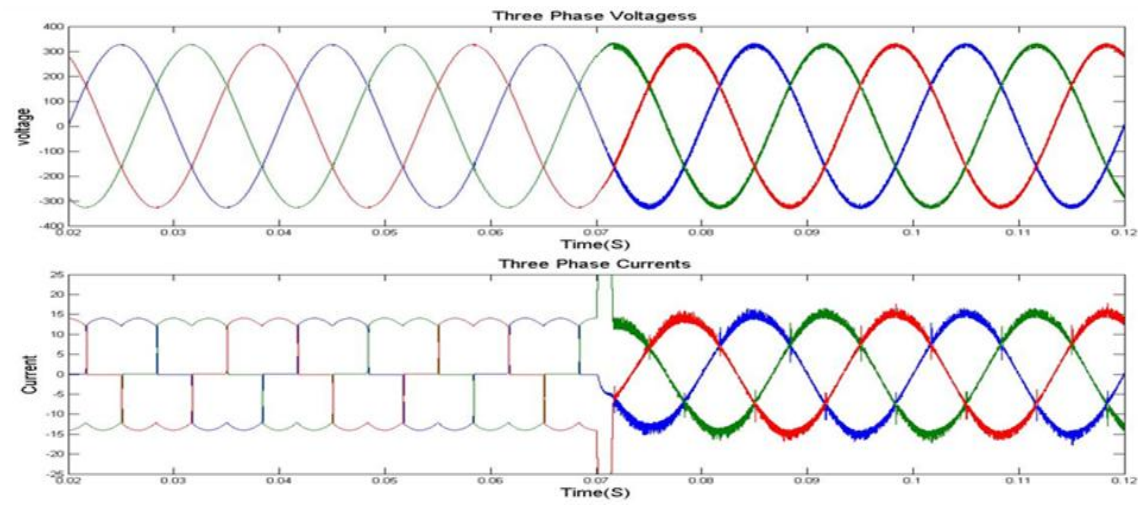

Fig.18. The change in source voltages and current 

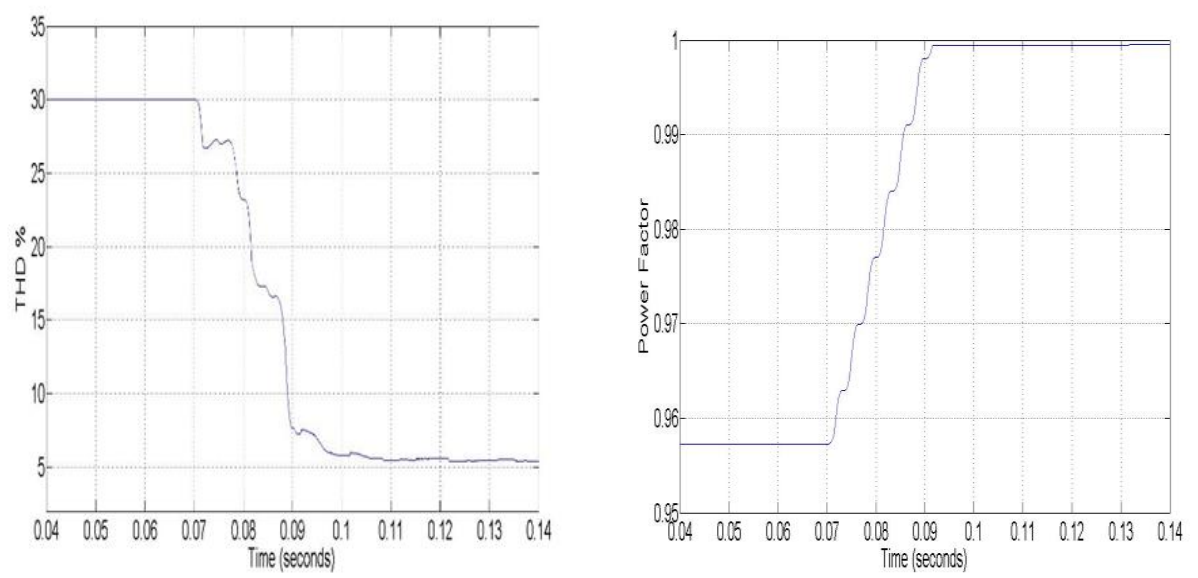

Fig.19. The improvement in THD and Power Factor after compensation

From all above results Table. 4 shows the change occurred to the Power quality elements either THD or power factor (P.F) values before and after using SAPF to prove how far SAPF effect on system quality improvement.

\section{Table 4. THD and P.F Comparison Table}

\begin{tabular}{|c|c|c|}
\hline Condition & THD \% & P.F \\
\hline Load Experimental Results & $30 \%$ & 0.96 \\
Load Simulation without SAPF & $30 \%$ & 0.96 \\
Load with SAPF & $9.5 \%$ & 0.99 \\
Load with SAPF-PSO & $5.5 \%$ & 0.99 \\
\hline
\end{tabular}

\section{CONCLUSION}

A detailed design of SAPF is introduced in this paper to prove that an enhancement of power quality in terms of THD in source current and the reactive power compensation are achieved The parameters of PI controller are designed based on conventional method and optimized with advanced PSO. It is found that the PSO gave accurate and best results. The value of THD in source currents is about $30 \%$ and reduced by SAPF to $9.5 \%$. By optimizing the 
gains of PI controller the THD value is reduced from $9.5 \%$ to $5.54 \%$. The virtual SAPF is used with a practical nonlinear load after modeling it to check its validity with any system .So it can be clearly stated that with the application of SAPF with the system, harmonics present in the source current are mostly compensated and by the optimization of PI controller using PSO technique further reduces the harmonics on the PCC of source side. The proposed filter can be adapted for any other loads with acceptable total harmonic distortion under the norms of IEEE (519-1992).

\section{References}

[1]Ned Mohan 2002, 'Power Electronics: Converters, Applications, and Design' 3rd Edition', Wiley publications.

[2] M.H.J. Bollen, 2003 "What is Power Quality?", Electric Power Systems Research, 66(1) 5-14

[3] F. Z. Peng, H. Akagi and A. Nabae, (1990). "A New Approach to Harmonic Compensation in Power System a Combined System of Shunt Passive and Series Active Filter”, IEEE Trans. On Industry App., 27(6) 983-990,

[4] Hamadi, A, Rahmani, S \& Al-Haddad, (2010). 'A hybrid passive filter configuration for VAR control and harmonic compensation', IEEE Trans. Ind. Electron, 57(7): 24192434 ,

[5] Hideaki Fujita and Hirofumi Akagi , 1991. "A Practical Approach to Harmonic Compensation in Power Systems series connection of Passive and Active Filters", IEEE Transactions on Industry Application , 27( 6),1020 -1025

[6] Kennedy, J, Eberhart, RC, 1995 'Particle Swarm optimization' IEEE International conference on neural network, Vol.4 Piscataway, NJ Institute of Electrical and Electronics Engineers, 1942-48

[7] N. Gowtham, Shobha Shankar,( 2016),'PI tuning of Shunt Active Filter using GA and PSO algorithm',2016 2nd International Conference on Advances in Electrical, 
Electronics, Information, Communication and BioInformatics (AEEICB), 980-990,

[8] Tugçe Demirdelen, Rahmi Ilker Kayaalp, Mehmet Tümay( 2016), 'PSO-PI Based DC Link Voltage Control Technique for Shunt Hybrid Active Power Filter'2016 International Conference on Systems Informatics, Modelling and Simulation (SIMS), 97-102.

[9] H. Akagi, Y. Kanazawa and A. Nabae, (1983). "Theory of Instantaneous Reactive Power and Its Applications", Transactions of the 1EE-Japan, Part B, 103(7), 483-490,

[10] M. Kale and E. Ozdemir, (2005)."Harmonic and reactive power compensation with shunt active power filter under non-ideal mains voltage," Electric Power System Research (Elsevier), 77, 363-370,

[11] B. Singh, K. Al-Haddad and A. Chandra,(1999). "A review of active filters for power quality improvement," IEEE Transactions on Industrial Electronics, 46(5), 960-971.

[12] Colak, I., Bayindir, R., Kaplan, O., \& Tas, F. (2010). DC bus voltage regulation of an active power flter using a fuzzy logic controller. In Machine Learning and Applications (ICMLA), Ninth International Conference on IEEE 692-696.

[13] Krim, F. (2011, June). Parameters estimation of shunt active flter for power quality improvement. In Power Engineering and Optimization Conference (PEOCO),5th International, IEEE, 306-311.

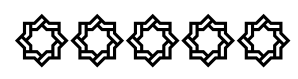




\section{المغص المربي}

\section{التصميم الأهثل لمرشح قدرة لتصمين جودة القدرة الكهربية بالاعتماد علي تقنية التزكيب المعمدي الافتزاضي للامرشح}

عيد جودة ${ }^{1}$ - حسام الشرباصي2 ${ }^{2}$ فريد نجيب عبد البر ${ }^{3}$ - جابر السعدي3

$$
\begin{aligned}
& \text { "قسم الهندسة الكهربائية - كالية الهندسسة - جاهعة المنصورة } \\
& \text { 20 ههندس كهرباء بالإدارة الهندسية بشركة الدقهلية للسكر } \\
& 3 \text { قسم الهندسة الكهربائسية - كلية الهندسة - جاهعة اسيوط }
\end{aligned}
$$

في الآونة الاخيرة تلعب مسالة الجودة فى نظم القوى الكهربية (جودة القدرة)

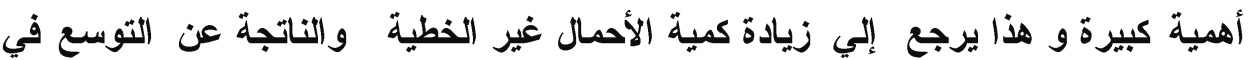

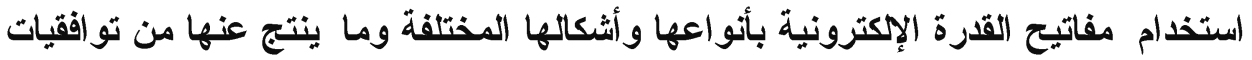

و انخفاض كبير في معامل القدرة مما يسبب مشاكل وأضر ار كثيرة للشبكات الكهربية بالإضافة إلي التأثير السلبى علي المعدات والاجزاء الكهربية المختلفة بسبب تثوه موجات

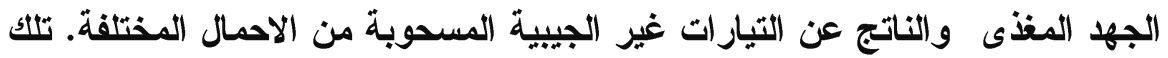

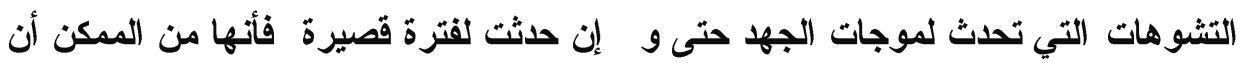
ينتج عنها خسائر كبيرة فى المكونات والأجزاء الكهربية المستخدمة. هذا وات المقال يتناول تصميم وتمثيل مرشح قدرة من النوع الموازي وذلك بتطبيقه افتراضيا على حمل مادى

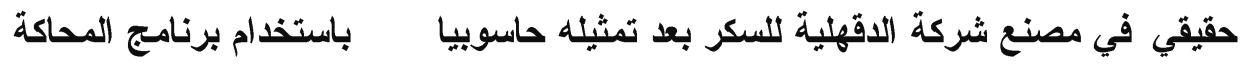

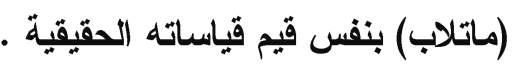
هذا المقال يعطى بعض الإسهامات البسيطة في مجال جودة القدرة مثثل : تصميم وتمثيل

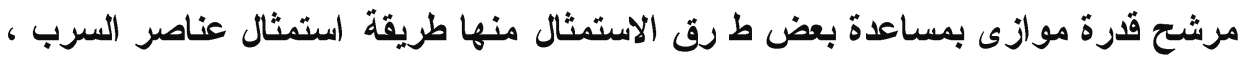
التصميم العملي والتمثيل الحاسوبي بنفس القيم والقياسات لحمل مادى حقيقي ودراسة مدى التى

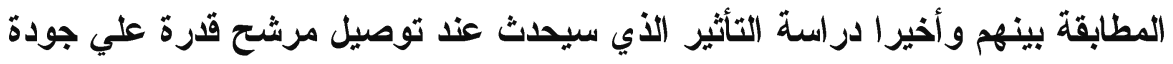

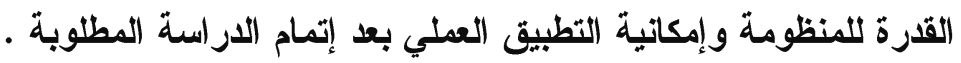

